\title{
Design and characterization of microstrip UWB antennas
}

\author{
Djamel ABED ${ }^{1}$ and Hocine KIMOUCHE ${ }^{2}$ \\ ${ }^{1}$ Telecommunication Laboratory, University of Guelma \\ ${ }^{2}$ Microwave and Radar Laboratory, Military Polytechnic School \\ Algeria
}

\section{Introduction}

Ultra-WideBand (UWB) technology was approved by the Federal Communications Commission (FCC) in February 2002 (FCC, 2002). According to the FCC regulations, the frequency band from 3.1 to $10.6 \mathrm{GHz}$ can be used for short-range and high speed wireless communications systems. This recent allocation of a very wide spectrum of frequencies for the devices uses, with effective isotropic radiated power (EIRP) less than $-41 \mathrm{dBm} / \mathrm{MHz}$ has presented numerous exciting opportunities and challenges for antenna designers. UWB antennas should be effective in transmitting, compact, non dispersive, and have a good wide impedance bandwidth properties, these features are desirable for both indoor and outdoor hand-held UWB applications. In practical UWB applications, microstrip antennas that can be directly printed onto printed circuit boards (PCBs) are the most promising candidates. Such a PCB antenna has a low profile, a low manufacturing cost and can easily be integrated with other parts of monolithic microwave integrate circuit (MMIC) for a transceiver or any other UWB system. To satisfy such requirements, various types of planar antennas have been developed for UWB communications over the last few years. Also, several bandwidth enhancement techniques have been reported, to improve the impedance bandwidth of these antennas. Microstrip UWB antennas are usually constructed by etching a radiator onto the dielectric substrate of a piece of the PCB and a partial ground plane onto the opposite side if the antenna is fed by microstrip transmission line or on the same side in the case of coplanar waveguide $(\mathrm{CPW})$ feeding. In the literature, many different microstrip UWB antennas with circular, elliptical, triangular, rectangular, hexagonal, and so on patches are currently being considered for UWB applications.

This chapter presents an overview of UWB antennas design an characterization, some novel designs were investigated and presented. The first class of studied UWB antennas is microstrip monopole antennas including the microstrip/CPW-fed modified - elliptical monopole antennas. The second class is for UWB slot antennas, where a novel stepped inverted cone slot antenna with different stub shapes is proposed for UWB applications. In the third class a notched band UWB antenna is presented; the proposed UWB have been developed to notch-band UWB antenna by inserting a U-shape slot into patch. The advantage of this approach is that the stop-band filter (slot) can directly integrated in antenna structure. The study includes detailed parametric analysis of the antennas performances with relation to the desirable properties for UWB antennas. 


\section{Microstrip UWB Monopole Antennas}

Microstrip UWB monopole antennas are usually constructed by etching the radiator element with a microstrip/CPW feeding structure and the partial ground plane on dielectric substrate. In this section we present two novel microstrip UWB monopole antennas.

\section{Printed Modified Elliptical Monopole (PMEM) Antenna}

The printed modified elliptical monopole (PMEM) antenna (Kimouche, 2009) shown in figure 1 is designed to cover the UWB band from $3.1 \mathrm{GHz}$ to $10.6 \mathrm{GHz}$. The antenna consists of modified-elliptic shaped radiator etched on a top side of PCB (FR4, $\varepsilon_{r}=4.32$, loss tang of 0.017 and $1.59 \mathrm{~mm}$ in thickness) and fed by 50-Ohms microstrip-line of width $W_{f}=$ $3 \mathrm{~mm}$. The modified semicircular - shaped ground with a rectangular notch defined by $\left(W_{n} \times\right.$ $\left.L_{n}\right) \mathrm{mm}$ is printed in the bottom side. A parametric study of microstrip-fed PMEM antenna on the main parameters of the patch radiator, and the partial modified-semicircular ground plane (on the back of substrate) has been optimized by using electromagnetic software simulator. The patch radiator connected to the microstrip-line is the result of two identical $1 / 4$ ellipse spaced by a distance $d$ fixed at $3 \mathrm{~mm}$ and placed in the part of circular-shaped base. Each $1 / 4$ ellipse is defined by the radius of the major axe $R_{1}$ and the radius of the minor axe $R_{2}$. The base is define by the height $D$, the major radius and the minor radius $r_{1}$ and $r_{2}$, respectively. The minor radius $R_{2}$ is fixed by the value of the parameter $D$. The elliptical ratio $(E R)$ defined by $E R=R_{2} / R_{1}$ has been optimized for five values of the parameter D.

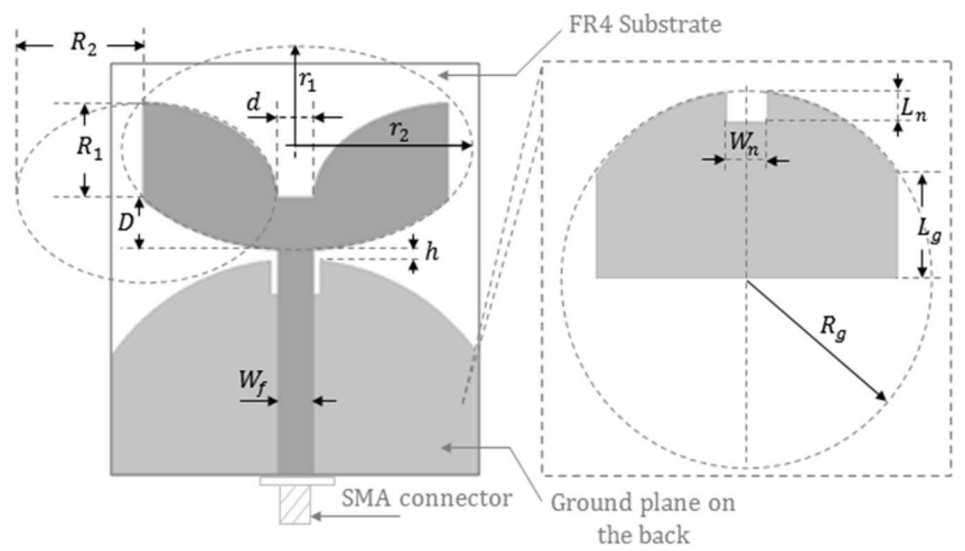

Fig. 1. Geometry of the Microstrip-fed PMEM Antenna

The simulated return losses as function of frequency for the five different values of $D$ and $E R$ are illustrated in figure 2. The optimal values of the patch radiator are found to be $D=4.45 \mathrm{~mm}, R_{1}=8 \mathrm{~mm}, R_{2}=8.8 \mathrm{~mm}, r_{1}=9.25 \mathrm{~mm}$, and $r_{2}=11.1 \mathrm{~mm}$. The effect of the distance $h$ between the modified elliptical patch radiator and the ground plane called feed gap is simulated for return loss as function of frequency. As shown in figure 3 , the return loss characteristics for the microstrip-fed PMEM antenna was simulated for different feed gaps $(h=0.3,0.5,0.7,1.5$, and 3$) \mathrm{mm}$. It is shown that the $-10 \mathrm{~dB}$ operating bandwidth of the antenna varies remarkably with the variation of the feed gap $h$, but the return loss 


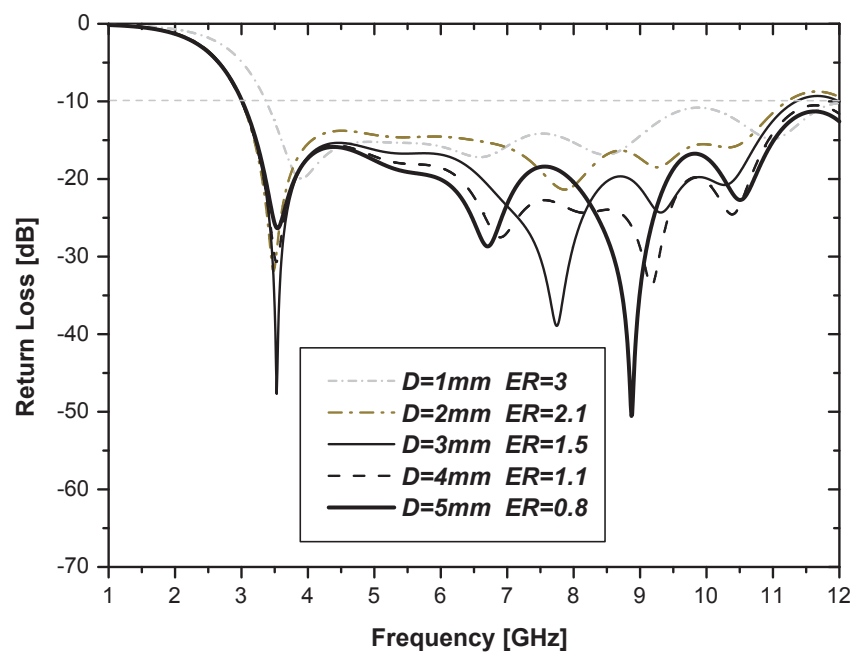

Fig. 2. The Effect of the Parameter $D$ and the Elliptical Ratio ER

curves have similar shapes for the different feed gaps. The optimal feed gap is found to be at $h=0.3 \mathrm{~mm}$. The shape of the ground plane is chosen to be a modified semi-circular with a rectangular notch. The ground plane size is defined by the radius $R_{g}$ and the length $L_{g}$. Figure 4 shows the simulated return loss curves with the optimal values $h=0.3$ $\mathrm{mm}$ and the previous optimal patch radiator parameters for different radius values $R_{g}$. It can be seen that the variation of the ground plane width shifts all the resonance modes across the spectrum. We noticed that the lower-edge frequency will decrease when the radius $R_{g}$ increase. Also, it is clear that most of the values of $R_{g}$ can achieve an ultra-wideband, for example the value $R_{g}=20 \mathrm{~mm}$ achieve a bandwidth of $13.34 \mathrm{GHz}(2.85-16.19 \mathrm{GHz})$.

Also, it is seen that the antenna bandwidth is sensitive to the variation of the parameter $L_{g}$. Figure 5 illustrates the return loss for different values of $L_{g}$. The optimized value was found to be $L_{g}=10.5 \mathrm{~mm}$.

The notch introduced in the ground plane is used to miniaturize the proposed microstrip-fed PMEM antenna and to improve its impedance matching. This technique is introduced in (Bao, 2007) to improve the impedance bandwidth of rectangular patch antenna and in (Kobayashi, 2007) to compact circular disc antenna. Figure 6 illustrates the simulated return loss curves of the proposed microstrip-fed PMEM antenna with and without the rectangular notch in the ground plane. It is observed that the ground plane with an optimal rectangular notch of $(3.5 \times 3) \mathrm{mm}$ improves significantly the impedance bandwidth and creates other resonant frequencies. 


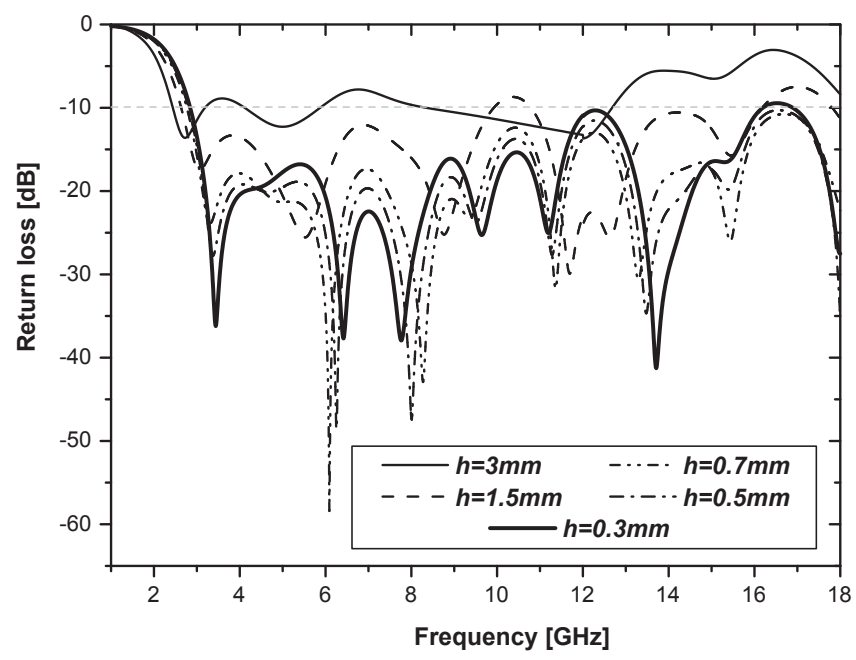

Fig. 3. The Effect of the Feed Gap $h$ of the Microstrip-fed PMEM Antenna

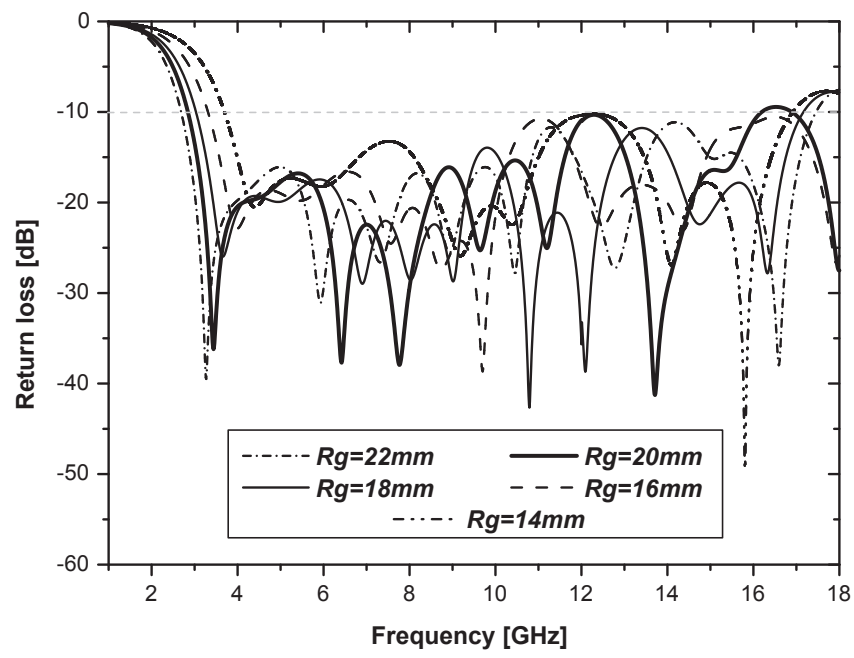

Fig. 4. The Effect of the Radius $R g$ of the Microstrip-fed PMEM Antenna 


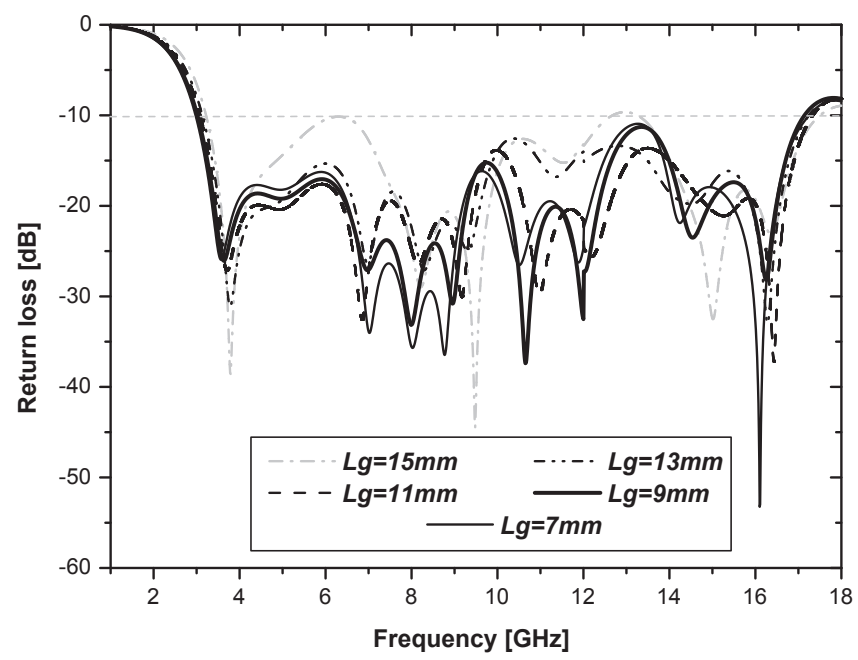

Fig. 5. The Effect of the Parameter $L g$ of the Microstrip-fed PMEM Antenna

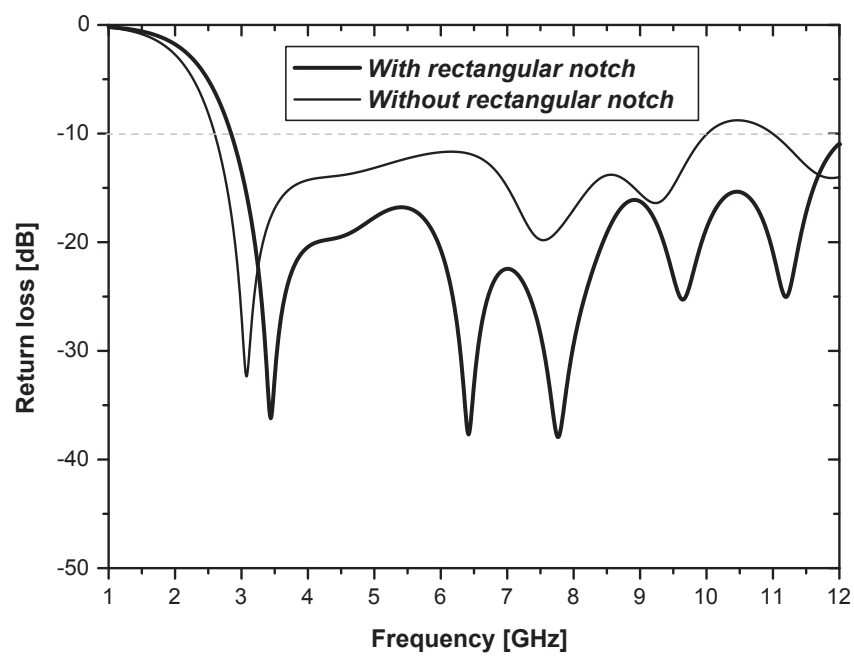

Fig. 6. The Effect of the Rectangular Notch in the Groundplane of the Microstrip-fed PMEM Antenna 
A prototype of the microstrip-fed PMEM antenna with optimal design, i.e. $h=0.3 \mathrm{~mm}$, $D=4.45 \mathrm{~mm}, R_{1}=8 \mathrm{~mm}, R_{2}=8.8 \mathrm{~mm}, r_{1}=9.25 \mathrm{~mm}, r_{2}=11.1 \mathrm{~mm}, d=3 \mathrm{~mm}, R_{g}=20 \mathrm{~mm}$, and $L_{g}=10.5 \mathrm{~mm}$, was fabricated and tested. Figures (7.a) and (7.b) present photographs of top side and bottom side of microstrip - fed PMEM antenna, respectively.

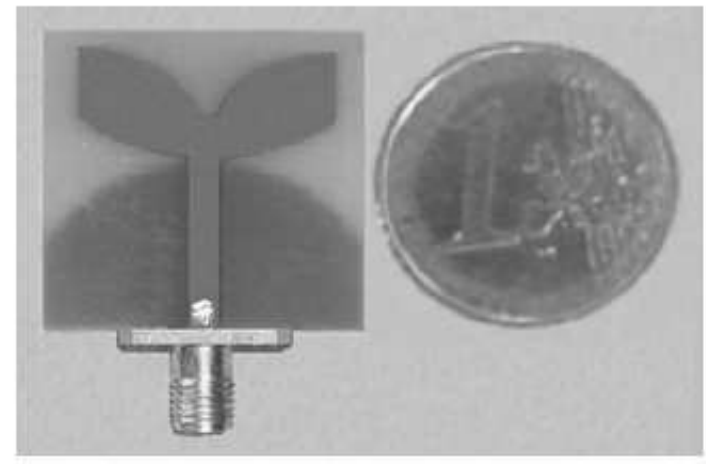

(a)

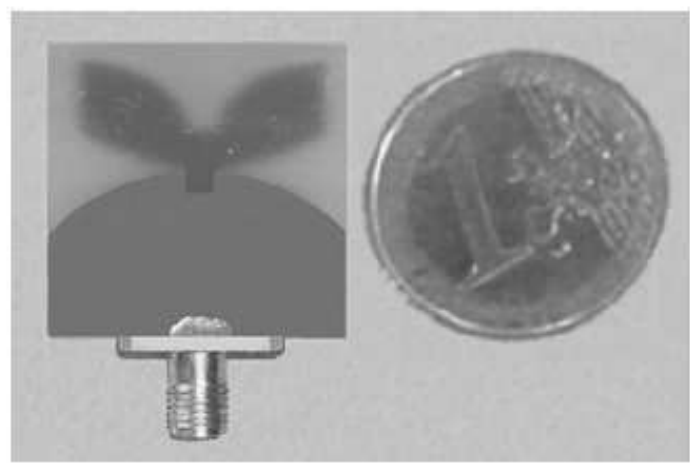

(b)

Fig. 7. Photographs of the Microstrip-fed PMEM Antenna. (a) Top Side, (b) Back Side

A Comparison between simulated return loss and measured return loss obtained by using an Agilent HP 8719ES vector network analyzer (VNA) is shown in figure 8. It is shown that the measured bandwidth of the proposed microstrip-fed antenna covers the FCC commercial UWB band with a fractional bandwidth of $113 \%$. 


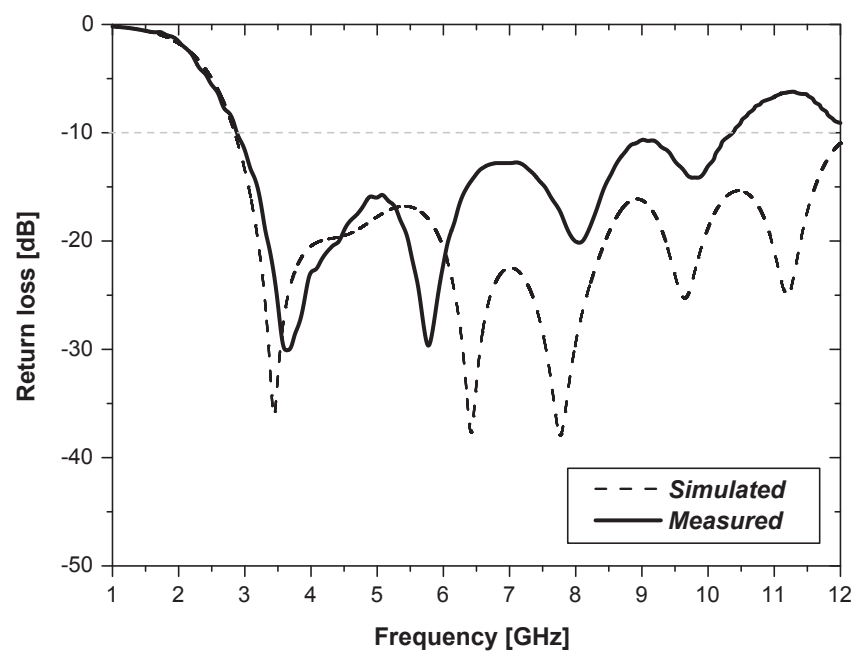

Fig. 8. Comparison between Simulated and Measured Return Loss Curves of the Microstripfed PMEM Antenna

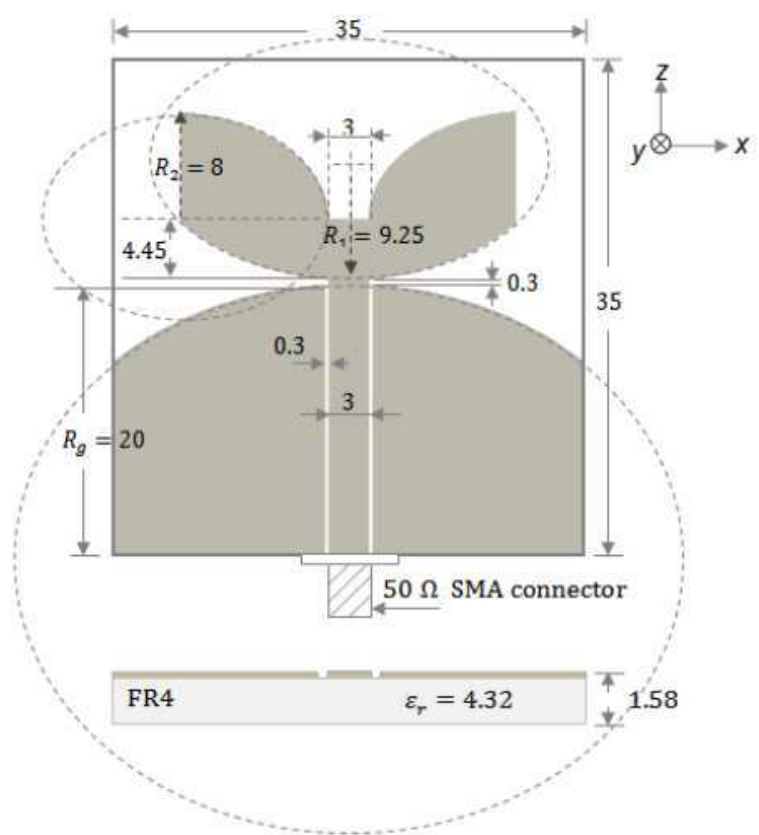

Fig. 9. Geometry of the Proposed CPW-fed PMEM Antenna 


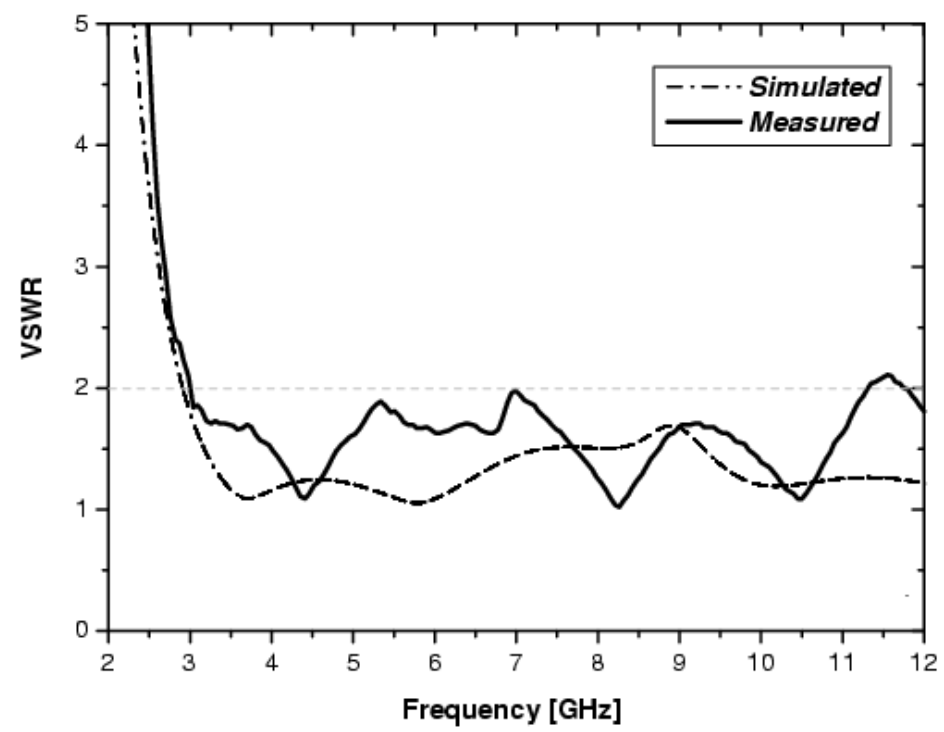

Fig. 10. Comparison between Simulated and Measured VSWR Curves of the CPW-fed PMEM Antenna

The previous proposed PMEM antenna can also fed by coplanar waveguide (CPW), in view of UWB applications. Figure 9 illustrates the configuration of the proposed CPW-fed PMEM antenna (Abed, 2008) with the optimal parameters, where an FR4 substrate with relative permittivity of 4.32 and thickness of $1.58 \mathrm{~mm}$ is used.

The CPW-fed PMEM antenna with the optimal geometrical parameters was fabricated. Measured and simulated VSWR (Voltage Standing Wave Ratio) are shown in figure 10. The measured bandwidth defined by VSWR $\leq 2$ of the proposed antenna with a feed gap of $0.3 \mathrm{~mm}$ is from $3 \mathrm{GHz}$ to $11.3 \mathrm{GHz}$, which covers the entire UWB band.

The far-field $(2 D)$ radiation patterns for the proposed CPW-PMEM antenna are also carried out at three frequencies. Figures (11.a) and (11.b) show the radiation pattern at azimuthal and elevation planes, respectively. As it can be seen from the figures, omnidirectional patterns can be observed for the $H$-plane. These patterns are comparable to those reported for a conventional dipole antenna. It is very important to note that at the higher frequency there is an obvious deviation from the omnidirectional shape in the $H$-plane radiation patterns. Also, the $E$-plane patterns have large back lobes at low frequency and with increasing frequency they become smaller, splitting into many minor ones. For the antenna gain, it is found that the proposed microstrip-fed PMEM antenna has a simulated maximum gain which varies between $0.18 \mathrm{dBi}$ and $3.61 \mathrm{dBi}$ within the UWB band.

By comparison with the microstrip-fed PMEM antenna, the CPW-fed PMEM antenna presents a less gain inside the UWB band with a peak gain of $2.98 \mathrm{dBi}$ at the frequency 5.6 $\mathrm{GHz}$. 


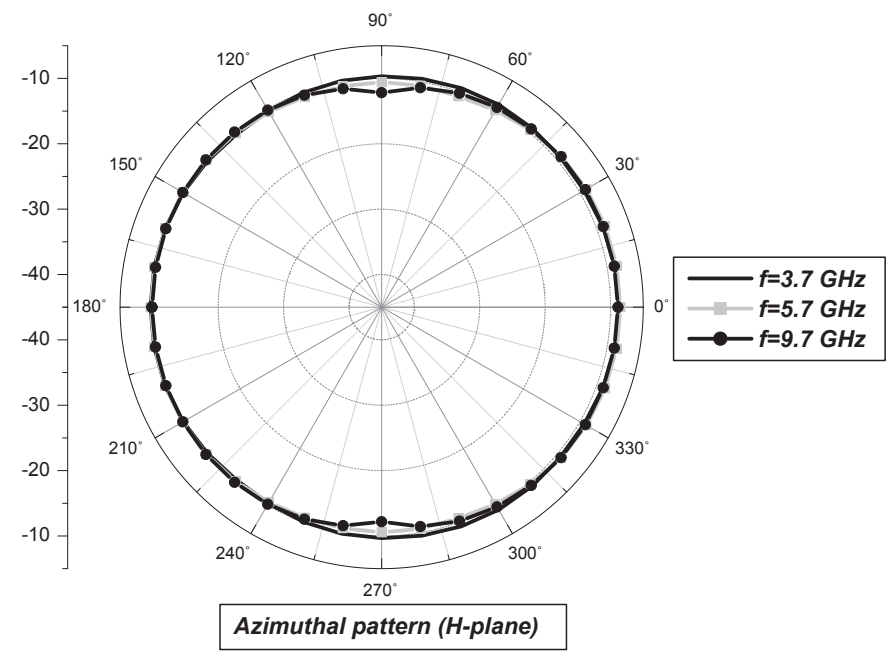

(a)

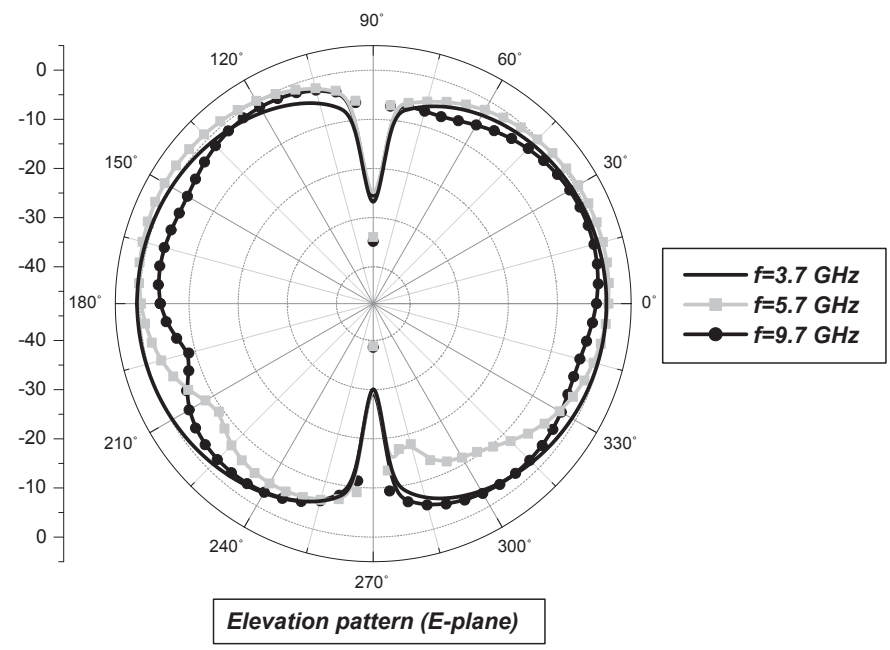

(b)

Fig. 11. Radiation Pattern of the CPW-fed PMEM Antenna. (a) Azimuthal Pattern (H-plane), (b) Elevation Pattern (E-plane) 


\section{Microstrip Slot UWB Antennas}

Various printed slot antenna configurations such as rectangle (Jang, 2000), (Chiou, 2003), (Chen, 2003) and (Liu, 2004), triangle (Chen, 2004) and (Chen, 2003), circle (Soliman, 1999) and (Sze, 2006), arc-shape (Chen, 2005), annular-ring (Chen, 2000) and others are proposed for narrowband and wideband application. In (Lee, 2002), a round corner rectangular wide slot antenna which is etched on a substrate with dimension of $(68 \times 50) \mathrm{mm}$, the measure $-10 \mathrm{~dB}$ bandwidth can achieve $6.17 \mathrm{GHz}(2.08 \mathrm{GHz}$ to $8.25 \mathrm{GHz})$. In (Chen, 2003), a CPW square slot antenna feed with a widened tuning stub can yield a wide impedance bandwidth of $60 \%$. The antenna has a dimension of $(72 \times 72) \mathrm{mm}$ and its gain ranges from $3.75 \mathrm{dBi}$ to $4.88 \mathrm{dBi}$ within the operational band. It is shown that the achieved bandwidths of these antennas cannot cover the whole FCC defined UWB frequency band from 3.1 GHz to $10.6 \mathrm{GHz}$. However, only a few microstrip / CPW-fed slot antennas with features suitable for UWB applications have been demonstrated in the literature. In (Chair, 2004), a CPW-fed rectangular slot antenna with a $\mathrm{U}$-shaped tuning stub can provide a bandwidth of $110 \%$ with gain varying from $1.9 \mathrm{dBi}$ to $5.1 \mathrm{dBi}$. Nevertheless, the antenna size is big $(100 \times 100) \mathrm{mm}$. The same for (Angelopoulos, 2006), where a microstrip-fed circular slot can operate over the entire UWB band, but with a slot diameter of $65.2 \mathrm{~mm}$. In (Denidni, 2006) and (Sorbello, 2005) UWB circular /elliptical $\mathrm{CPW}-\mathrm{fed}$ slot and microstrip-fed antennas designs targeting the $3.1-10.6 \mathrm{GHz}$ band. The antennas are comprised of elliptical or circular stubs that excite similar-shaped slot apertures. The same slots shapes were excited by a U-shaped tuning stub in (Liang, 2006), where an empirical formula is introduced to approximately determine the lower edge of the $-10 \mathrm{~dB}$ operating bandwidth. Others UWB slots antenna are proposed in (Sadat, 2007) and (Cheng, 2007). In this section, the microstrip-fed PSICS antenna configuration is investigated for UWB communications.

\section{Stepped Inverted Cone Slot Antennas}

The configuration of the proposed printed stepped inverted cone slot (PSICS) antenna is shown in figure 12. The proposed antenna with different feeding stubs is designed to cover the entire UWB band. The PSICS antenna consists of stepped inverted-cone shaped stub on the top side of $(50 \times 52) \mathrm{mm}\left(\mathrm{FR} 4, \varepsilon_{r}=4.32\right.$, loss tang of 0.017 and $H=1.59 \mathrm{~mm}$ in thickness) fed by $50-$ Ohms microstrip-line of width $W_{f}=3 \mathrm{~mm}$. The ground plane with the inverted stepped cone slot is printed on the bottom side.

A parametric study of the proposed PSICS UWB antenna on the main parameters of the stepped inverted-cone slot in the ground plane and the feeding stub structure are optimized by using an electromagnetic simulator based on the Method of Moment (MoM).

The effect of the parameters $R_{s}, L_{s 1}, L_{s 2}, W_{s 1}, W_{s 2}$ and $W_{s 3}$ which define the inverted-cone shaped slot was carried out. The good frequency bandwidth $(2.21 \mathrm{GHz}-11.5 \mathrm{GHz})$ was found for a radius $R_{s}=20 \mathrm{~mm}$ and the optimal values of the parameters $L_{s 1}, L_{s 2}, W_{s 1}, W_{s 2}$ and $W_{s 3}$. These values are presented in the table below.

\begin{tabular}{|c|c|c|c|c|c|}
\hline Parameter & $L_{s 1}$ & $L_{s 2}$ & $W_{s 1}$ & $W_{s 2}$ & $W_{s 3}$ \\
\hline Optimal value $(\mathrm{mm})$ & 2 & 6 & 4.5 & 3.5 & 21.5 \\
\hline
\end{tabular}

Table 1. Optimal Values of the Stepped Inverted-Cone Slot Parameters 

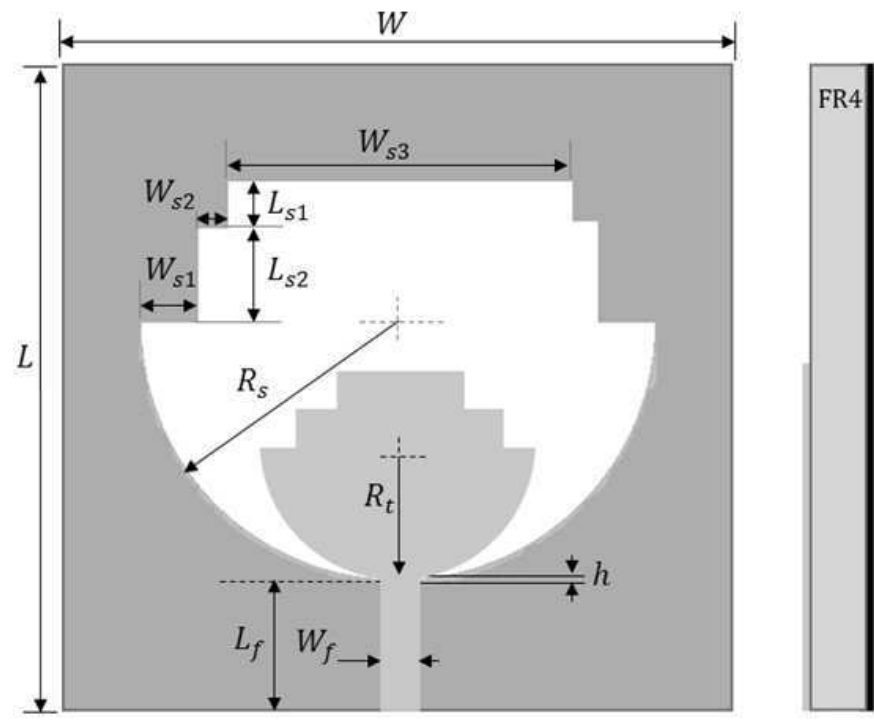

Fig. 12. Geometry of the Microstrip-fed PSICS UWB Antenna

The tuning stub of the PSICS antenna has the same shape as the slot. It is also, defined by the radius $R_{t}$ and the parameters $L_{t 1}, L_{t 1}, W_{t 1}, W_{t 2}$ and $W_{t 3}$, as shown in figure13.

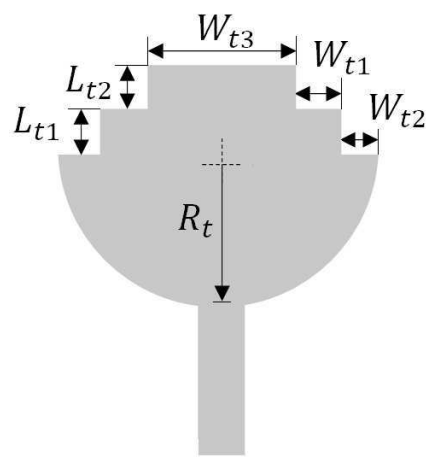

Fig. 13. The Parameters of the Stepped Inverted-Cone Stub

The optimal feed tuning stub radius is found to be at $R_{t}=10 \mathrm{~mm}$, with an extremely bandwidth range from $2.21 \mathrm{GHz}$ to $11.5 \mathrm{GHz}$. Also, it seems that when the value of the parameters $L_{t 1}, L_{t 2}$ and $L_{t 3}$ decrease, the first resonance shift to the low frequency but the antenna bandwidth decrease. The optimal values of the stepped-inverted cone stub parameters are presented in the table 2 . 


\begin{tabular}{|c|c|c|c|c|c|}
\hline Parameter & $L_{t 1}$ & $L_{t 2}$ & $W_{t 1}$ & $W_{t 2}$ & $W_{t 3}$ \\
\hline Optimal value $(\mathrm{mm})$ & 2 & 4.5 & 6 & 3 & 4 \\
\hline
\end{tabular}

Table 2. Optimal Values of the Stepped Inverted-Cone Stub Parameters

In order to optimize the coupling between the microstrip-line and the stepped inverted-cone slot. The stepped inverted-cone stub was compared with two different stubs as shown in figure 14. The first one is an inverted-cone and the second stub has a circular shape.

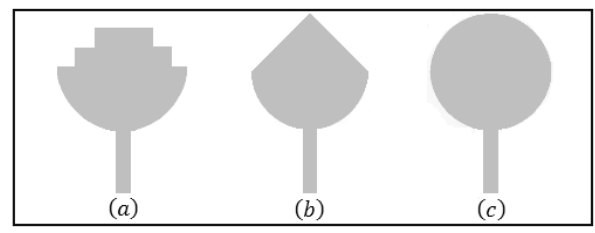

Fig. 14. Different Stub Shapes Studied for the Microstrip-fed PSICS UWB Antenna

The return loss of the microstrip-fed PSICS antenna was simulated for the three proposed stubs. Figure 15 illustrates a comparison between simulated return loss curves.

It shown that all the proposed antenna stubs have similar return loss curves, with an ex-

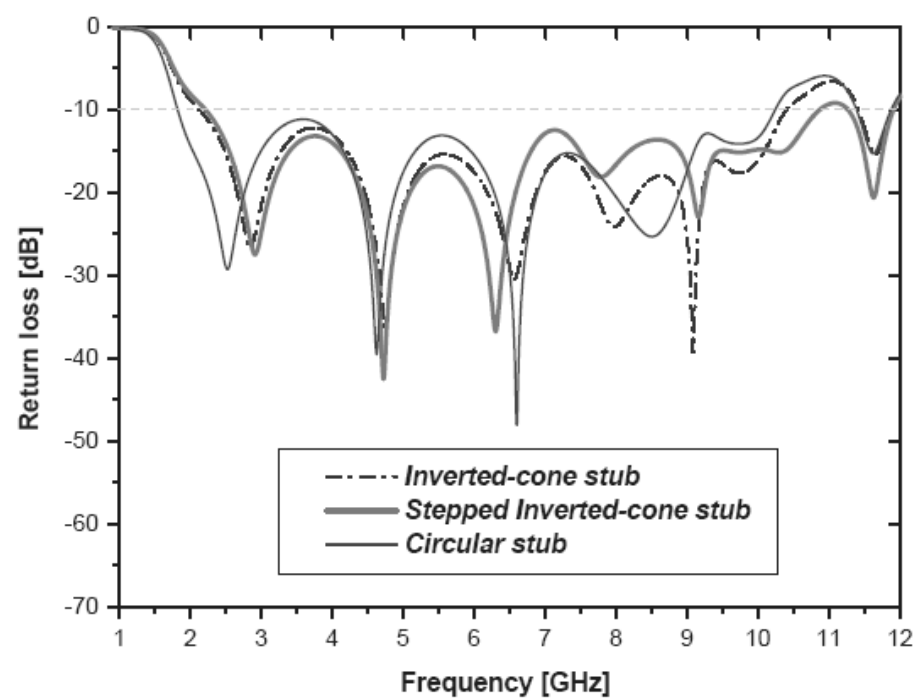

Fig. 15. Return Loss Curves of the Microstrip-fed PSICS Antenna for Different Stubs

tremely $-10 \mathrm{~dB}$ bandwidth which can covers the FCC UWB band. It is notice that the stepped inverted-cone slot increase significantly the possibility of the antenna feeding. 


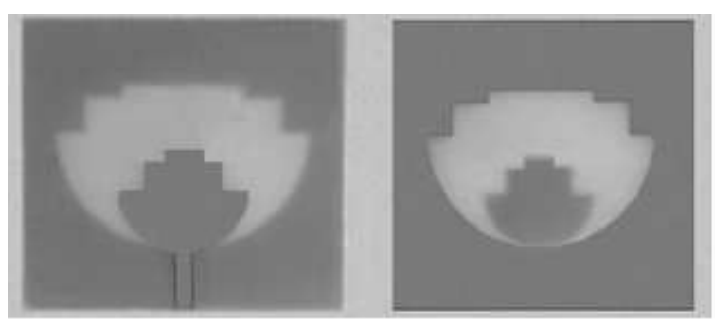

(a)

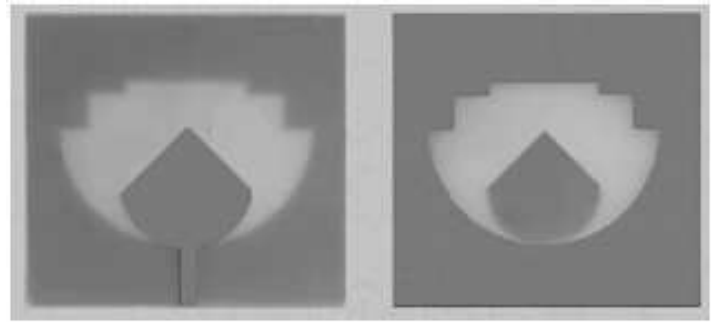

(b)

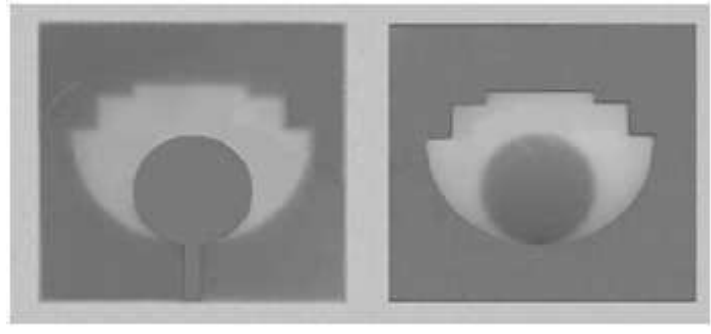

(c)

Fig. 16. Photographs of Realized Microstrip-fed PSICS Antennas. (a) with Stepped Inverted-Cone Stub, (b) with Inverted-Cone Stub, (c) with Circular Stub

Three prototypes of the microstrip-fed PSICS antenna with three different stubs in optimal design, was fabricated and tested. Figures (16.a), (16.b) and (16.c) present photos of PSICS antenna with stepped inverted-cone stub, inverted - cone stub and circular stub, respectively.

The return losses were measured by using vectorial network analyzer. Figures (17.a), (17.b) and (17.c) illustrate a comparison between simulated and measured return loss curves of the PSICS antenna with stepped inverted-cone stub, inverted-cone stub and circular stub, respectively. Generally speaking, as illustrated in figure(17.a), the measured return loss curve agrees with the simulated one in most range of the low frequencies band. 


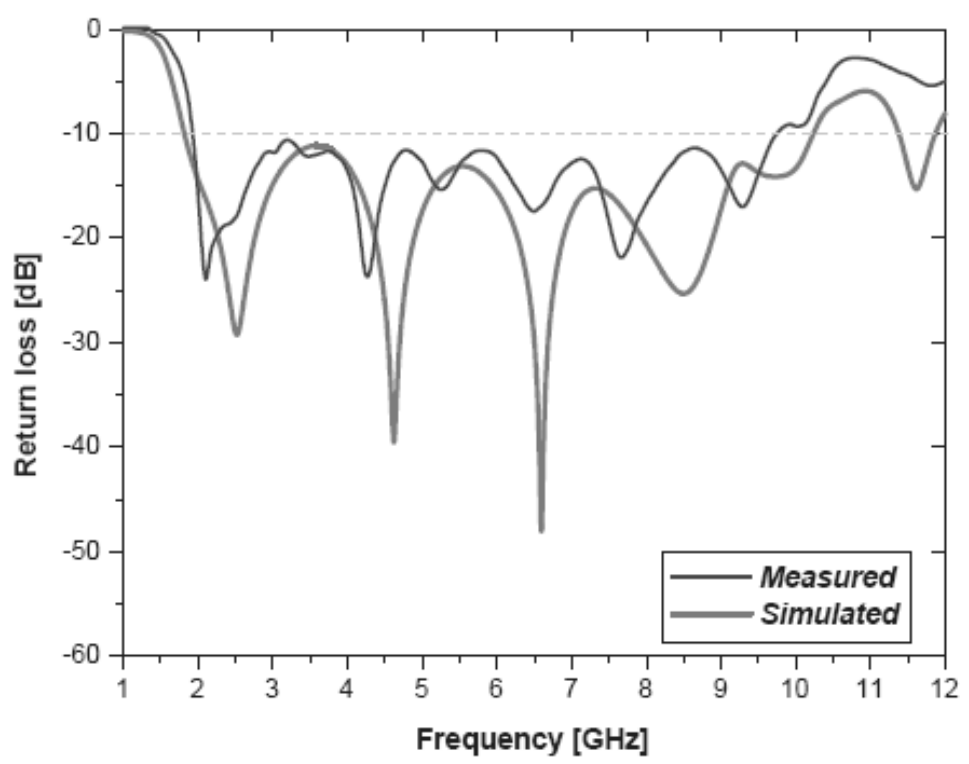

(a)

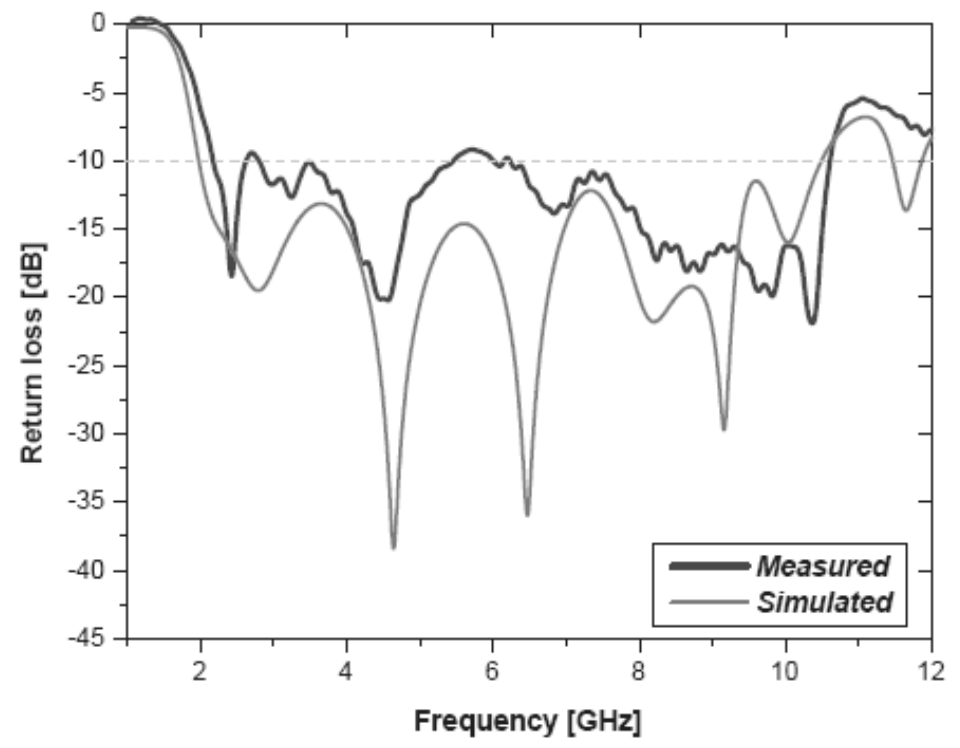

(b) 


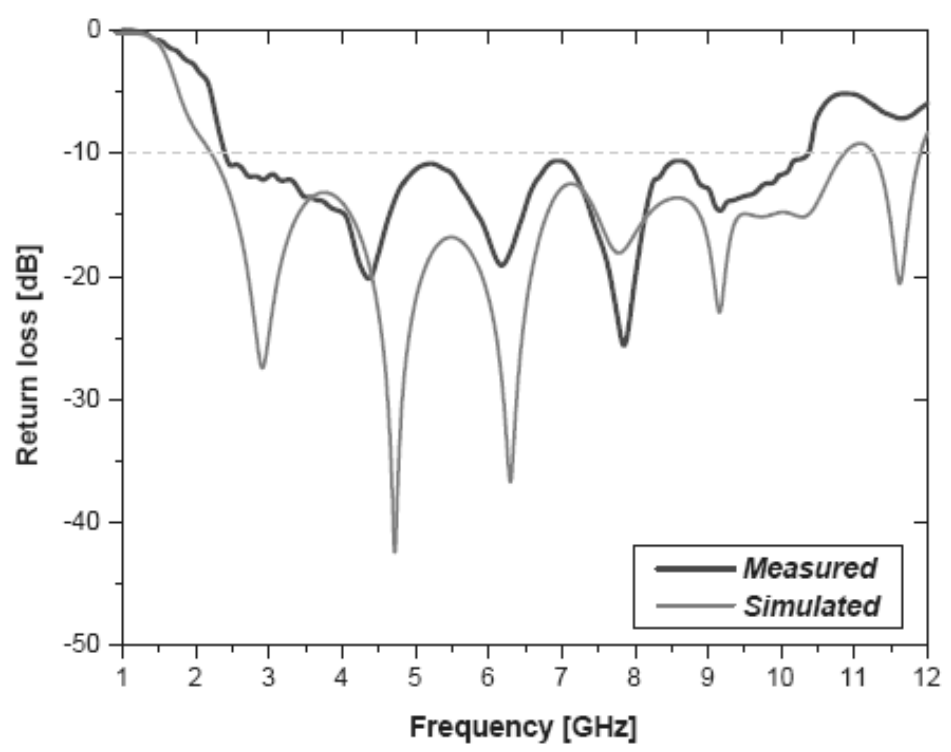

(c)

Fig. 17. Comparison between Simulated and Measured Return loss Curves of the Microstripfed PSICS UWB Antennas. (a) with Stepped Inverted-Cone Stub, (b) with Inverted-Cone Stub, (c) with Circular Stub

The $-10 \mathrm{~dB}$ bandwidth covers an extremely wide frequency range in both simulation and measurement. In figure(17.b), the UWB characteristic of the microstrip-fed PSICS antenna with a circular stub is confirmed in the measurement. It is shown that there is a good agreement between simulated and measured lower edge frequencies. However, there is significant difference between simulated and measured high edge frequencies.

The far-field radiation patterns of the PSICS antennas were also simulated at three frequencies. Figure 18 shows the radiation pattern of PSICS antenna with the inverted-cone stub at azimuthal and elevation planes. It is very important to note that the PSICS antenna with the different feeding structures can provide similar radiation patterns. As can be seen from the figure, omnidirectional patterns can be observed for the $H$-plane. 


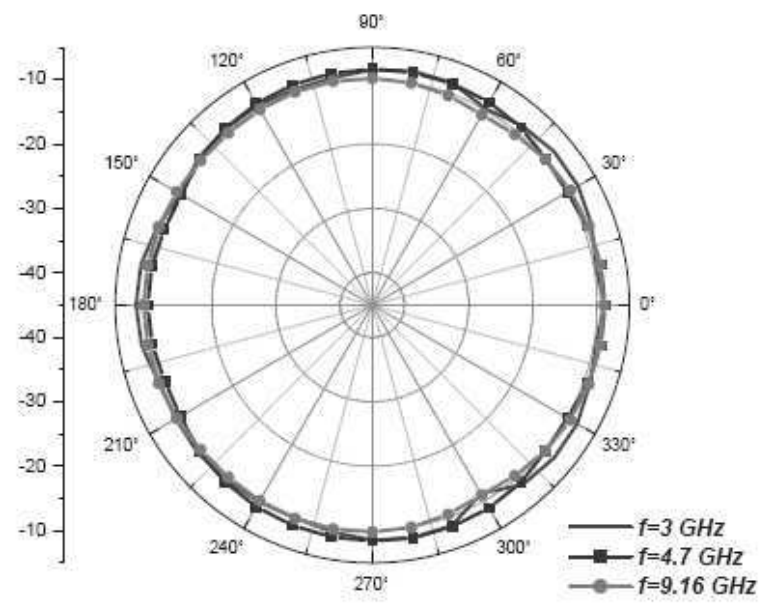

(a)

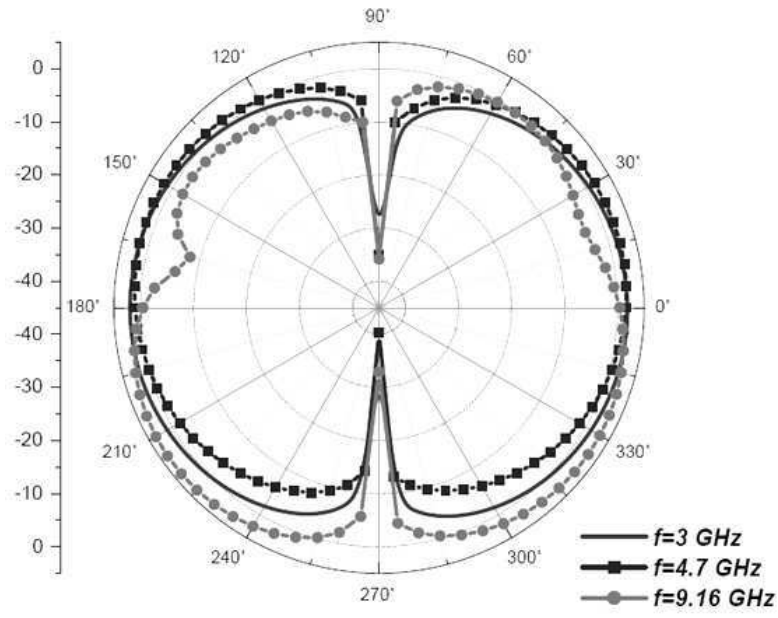

(b)

Fig. 18. Radiation Pattern of the Microstrip-fed PSICS Antenna with Steped-Inverted Cone Stub. (a) Azimuthal Pattern (H-plane), (b) Elevation Pattern (E-plane)

\section{Microstrip Frequency Notched UWB Antennas}

UWB technology is becoming an attractive solution for wireless communications, particularly for short and medium-range applications. UWB systems operate over extremely wide frequency bands (wider than $500 \mathrm{MHz}$ ), according to the FCC regulations, the unlicensed usage of UWB systems for the indoor communications has been allocated to the spectrum from 3.1 to $10.6 \mathrm{GHz}$. Within this UWB band, various narrowband technologies also operate with much higher power levels, as illustrated in figure 19. It is clear, that there is frequency-band sharing between the FCC's UWB band and the IEEE 802.11a. $(5.15-5.825 \mathrm{GHz})$ frequency 
band and the wireless local area networks bands: HiperLAN $(5.150-5.350 \mathrm{GHz})$ and WLAN $(5.725-5.825 \mathrm{GHz})$. Therefore, it may be necessary to have a notch for this band in order to avoid interferences. Recently, various suppression techniques have been developed for UWB communications to improve the performance, the capacity and the range. Some techniques are used at the receiver stage, including notch filtering (Choi et al, 1997), linear and nonlinear predictive techniques (Rusch, 1994), (Rusch, 1995), (Proakis, 1995), (Carlemalm, 2002) and (Azmi, 2002), adaptive methods (Lim et al., 1996) and (Fathallah et al., 1996), MMSE detectors (Poor, 1997) and (Buzzi, 1996), and transform domain techniques (Buzzi et al., 1996), (Medley, 1997), (Weaver, 2003) and (Kasparis, 1991). Another approach for interference suppression is used at the antenna. Based on this approach various frequency-notched UWB antennas have been developed by inserting diffident slot shapes (Chen, 2006), (Hong, 2007), (Yan, 2007), (Yuan, 2008) and (Wang, 2008).

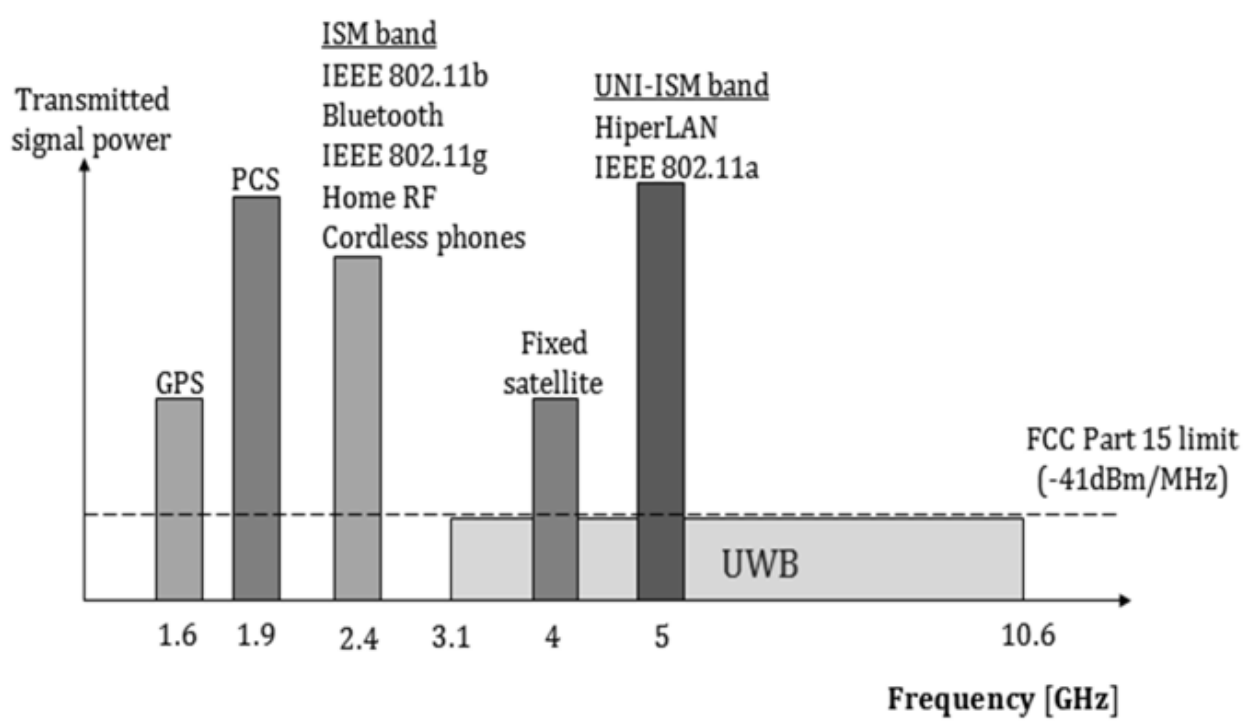

Fig. 19. The Coexistence of the UWB System and the Others Narrowband Systems

The advantage of this approach is that the stop-band filter (slot) is integrated directly in the antenna structure, and this is very important for communication devices which become smaller and more compact. In this section, we present the ability to achieve frequency notching characteristics in the previous proposed PMEM antenna by using the U-slot technique. The geometry of the notched-band PMEM antenna is shown in figure 20. The U-shaped slot introduced in the patch radiator is designed to notch the WLAN band. 


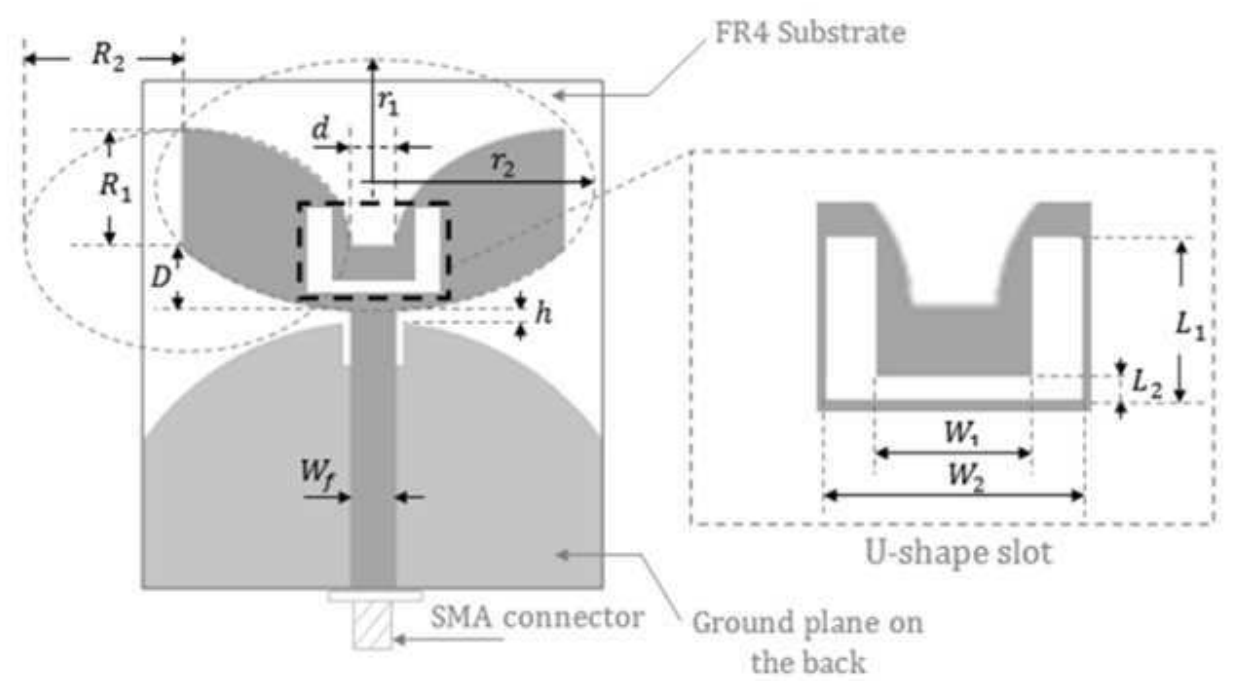

Fig. 20. Geometry of the Notched-Band Microstrip-fed PMEM UWB Antenna

The optimal values (in $\mathrm{mm}$ ) of the patch radiator and the ground plane are presented in the table 3 .

\begin{tabular}{|c|c|c|c|c|c|}
\hline Parameter & $L_{t 1}$ & $L_{t 2}$ & $W_{t 1}$ & $W_{t 2}$ & $W_{t 3}$ \\
\hline Optimal value $(\mathrm{mm})$ & 2 & 4.5 & 6 & 3 & 4 \\
\hline
\end{tabular}

Table 3. Optimal Values of the U-Shape Slot

\section{Band-notch function study}

The influence of the parameters $L_{1}, L_{2}, W_{1}$, and $W_{2}$ of the U-shaped slot introduced in the patch radiator are studied. To see the influences on the performance of the antenna an EM simulator is used. It is seen that by embedding the U-slot on the radiation patch, bandnotched characteristic is obtained.

Figure (21.a), shows the VSWR of the antenna with different $L_{1}$ of the slot location as the length $L_{2}$ are fixed at $0.75 \mathrm{~mm}$. It is seen that when $L_{1}$ is between $4.1 \mathrm{~mm}$ and $4.3 \mathrm{~mm}$, the antenna has a band-notch function at the WLAN band.

Figure (21.b) shows the VSWR of the antenna for different values of $L_{2}$. It is seen that the length of the slot determines the frequency range of the notched band. As $L_{2}$ increases, the notched band shifts toward the higher frequency. It is found that by adjusting the length of slot to be about $0.75 \mathrm{~mm}$ a notched frequency band of about $5.6-5.95 \mathrm{GHz}$ is obtained.

Figures (22.a) and (22.b) show the VSWR of the antenna with different slot widths $W_{1}$ and $W_{2}$, respectively. It is seen that when $W_{1}$ is smaller than $2 \mathrm{~mm}$, the antenna has a band-notch function at the WLAN band. 


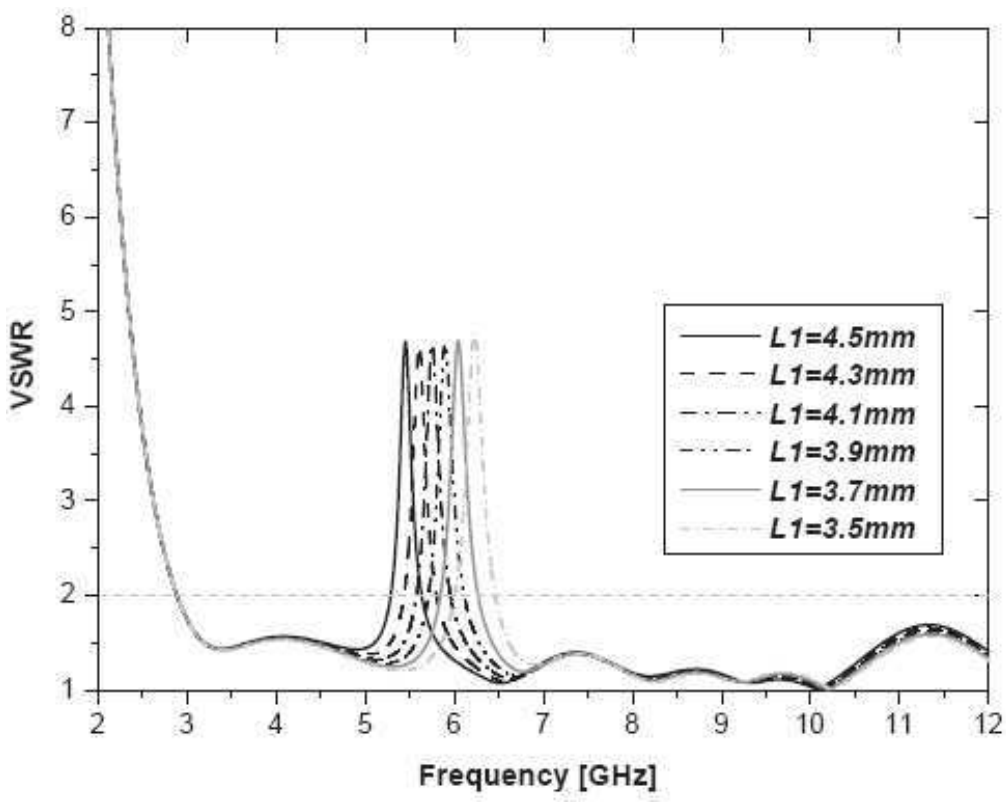

(a)

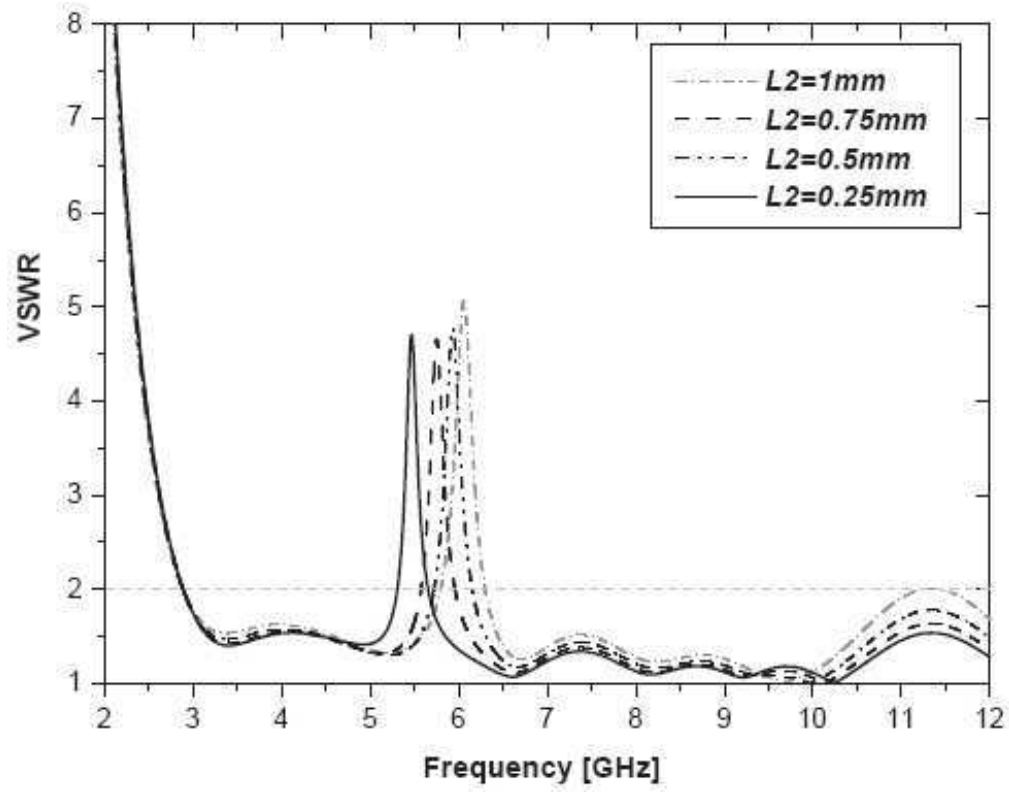

(b)

Fig. 21. VSWR versus U-Shape Slot Parameters. (a) The Effect of L1, (b) The Effect of L2 


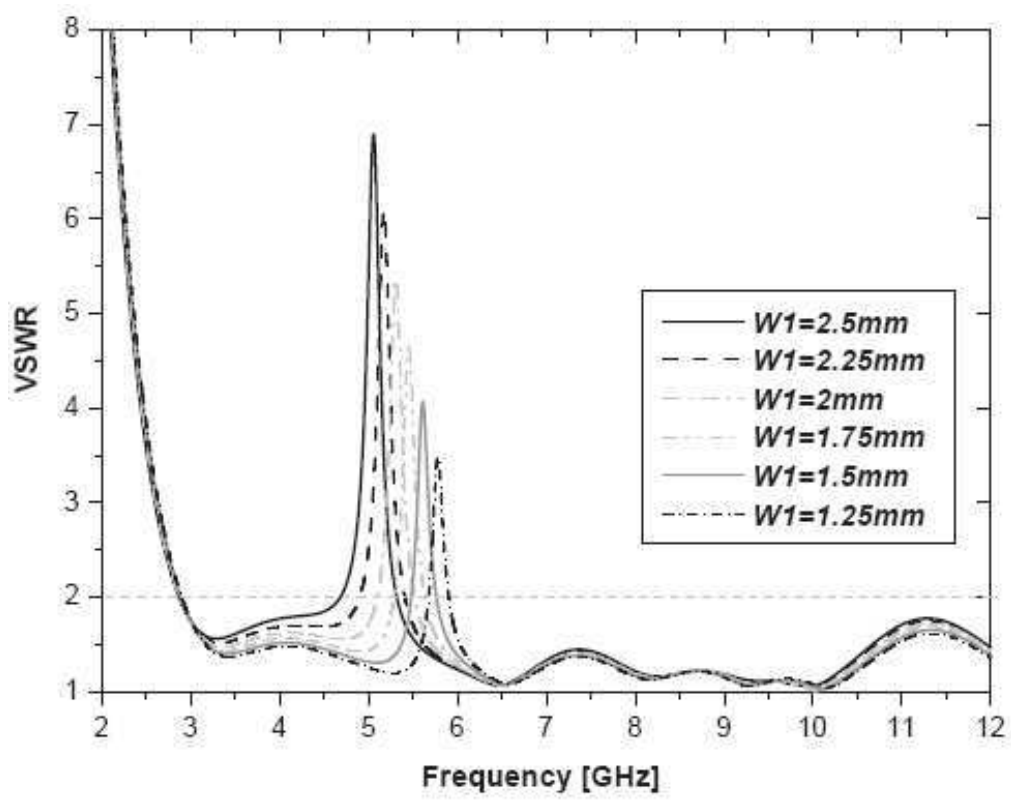

(a)

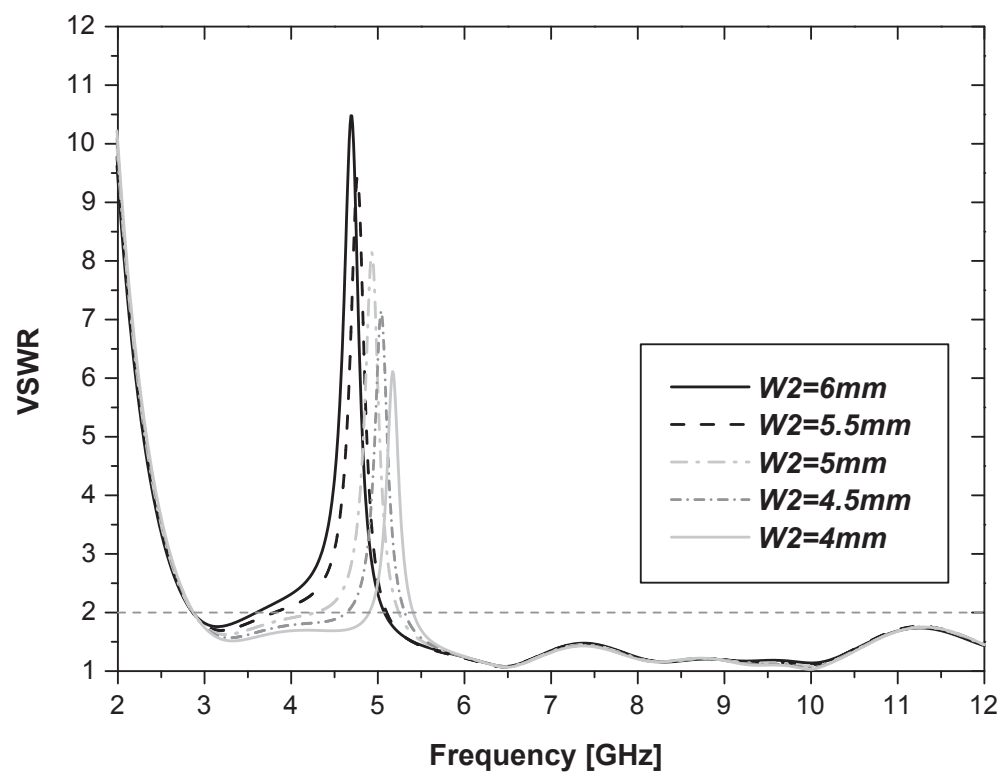

(b)

Fig. 22. VSWR versus U-Shape Slot Parameters. (a) The Effect of W1, (b) The Effect of W2 
A prototype of the microstrip-fed notched-band PMEM antenna with optimal design, was fabricated as shown in figure 10. A comparison between simulated return loss and measured return loss obtained by using a VNA is shown in figure 24 .

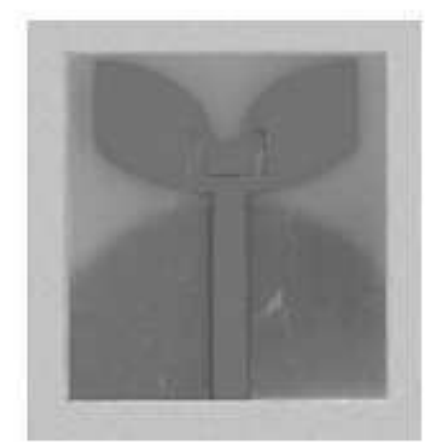

(a)

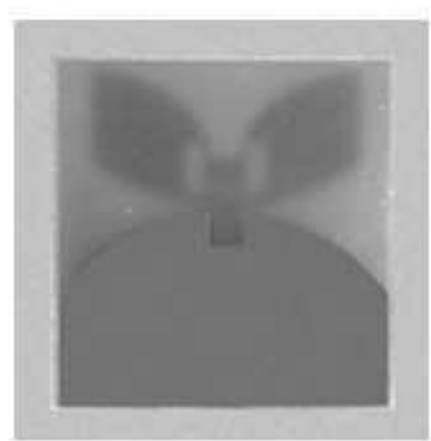

(b)

Fig. 23. Photographs of Realized Notched-Band PMEM UWB Antenna. (a) Top Side, (b) Back Side

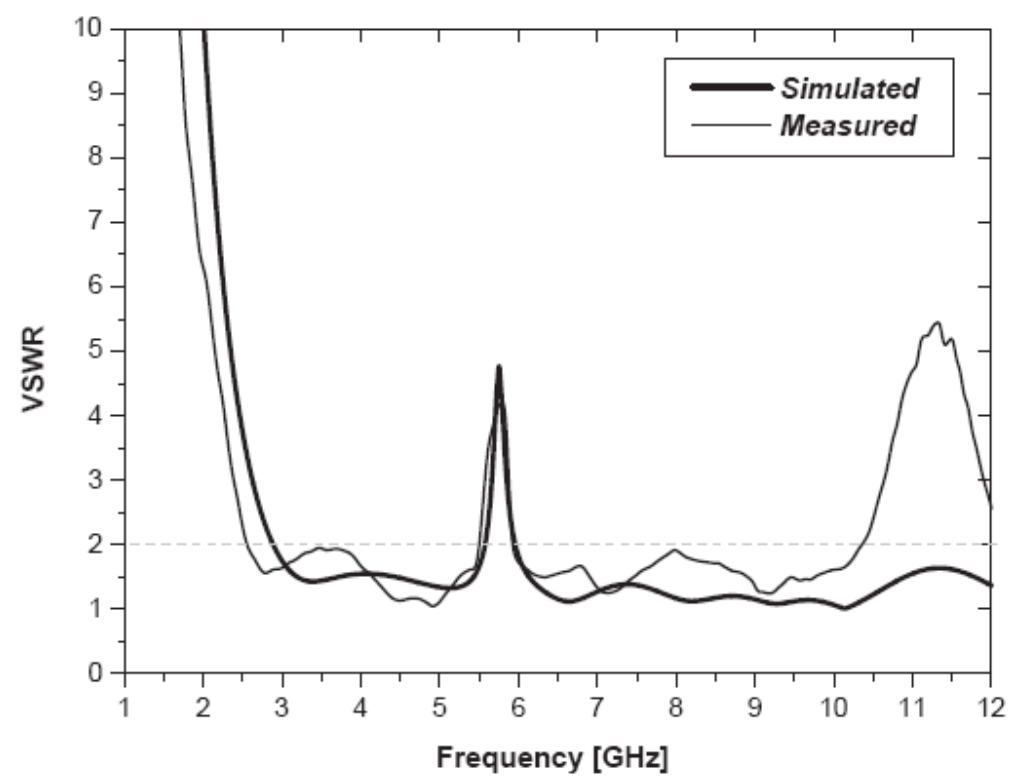

Fig. 24. Comparison between Simulated and Measured VSWR Curves of the Notched-Band Microstrip-fed PMEM UWB Antenna 
It is shown that there is a good agreement between simulated and measured VSWR curves at the most range. However, after the frequency $10.4 \mathrm{GHz}$ the measured VSWR will be greater than 2, where the simulated one remains less than 2. In other words a frequencynotch function at WLAN band is investigated. This characteristic is very attractive for UWB applications.

\section{Acknowledgement}

The authors acknowledge Dr. Attrouz, B. chief of Microwave and radar laboratory at Military Polytechnic School (EMP) in Algeria for his help in antenna prototypes realization/measurement and his very useful discussions and motivation.

\section{References}

Abed, D. Kimouche, H. and Atrouz, B. (2008). Small-size printed CPW-fed antenna for ultrawideband communications. IEE Electronics Letter, Vol. 44, No. 17, (August 2008) 3 $(1246-1248)$

Akansu, A., Tazebay, M. Medley, M. and Das, P. (1997). Wavelet and subband transforms: fundamentals and communication applications. IEEE Commun. Mag., Vol. 35, (December 1997) $11(104-115)$

Angelopoulos, E. S., Anastopoulos, A.Z. Kaklamani, A. A. Alexandridis, F.L. and Dangakis, K. (2006). Circular and Elliptical CPW-fed Slot and Microstrip-fed Antennas for Ultrawideband Applications. IEEE Antennas and Wireless Propagation Letters, Vol. 5 (2006) 4 (294-297)

Azmi, P. and Nasiri-Kenari, M. (2002). Narrow-band interference suppression in CDMA spreadspectrum communication systems based on sub-optimum unitary transforms. IEICE Trans. Commun., Vol. E85-B, No. 1, (January 2002) 8 (239-246)

Bao, X.L. and Ammann, M. J. (2007). Investigation on UWB printed monopole antenna with rectangular slitted ground plane. Microwave and Optical Technology Letter, Vol. 49, (2007) 3 (1585 - 1587)

Buzzi, S., Lops, M. \& Tulino, A. (1996). Time-varying mmse interference suppression in asynchronous DS/CDMA systems over multipath fading channels, Proceedings of IEEE Int. Symp. on Personal, Indoor and Mobile Radio Communications, pp. 518-522, September, 1998

Carlemalm, C. Poor, H. V. and Logothetis, A. (1996). Suppression of multiple narrowband interferers in a spread-spectrum communication system. IEEE J. Select. Areas Commun., Vol. 18, No. 8, (August 2000) 10 (1365-1374)

Chair, R., Kishk, A.A. and Lee, K.F. (2004). Ultrawide-band Coplanar Waveguide-fed Rectangular Slot Antenna. IEEE Antennas and Wireless Propagation Letters, Vol. 7, No. 12 (2004) 3 (227-229)

Chen,W.-S, Huang, C.-C. and Wong, K.-L. (2000). A novel microstrip-line-fed printed semicircular slot antenna for broadband operation. Microwave and Optical Technology Letters, Vol. 26, No. 4, (August 2000) 3 (237-239)

Chen, H. D. (2003). Broadband CPW-fed Square Slot Antennas with A Widened Tuning Stub. IEEE Transactions on Antennas and Propagation, Vol. 51, No. 8, (August 2003) 5 (19821986) 
Chen, W.-S. and Hsieh, F.-M. (2004). Broadband design of the printed triangular slot antenna. IEEE Antennas and Propagation Society International Symposium, Vol. 4, (June 2004) 4 (3733-3736)

Chen, J.-S. (2006). Dual-frequency annular-ring slot antennas fed by CPW feed and microstrip line feed. IEEE Transactions on Antennas and Propagation, Vol. 53, No. 1, (January 2005) $2(569-571)$

Chen, H.-D., Li, J.-N. and Huang, Y.-F. (2006). Band-notched ultra-wideband square slot antenna. Microwave and Optical Technology Letters, Vol. 48, No. 12, (December 2006) 3 (2427-2429)

Cheng, P. and Rydberg, A. (2008). Printed Slot Inverted Cone Antenna for Ultra Wideband applications. IEEE Antennas and Wireless Propagation Letters, Vol. 7 (2008) 4 (18-21)

Jang, Y.W. (2003). A Broad-Band CPW-Fed Strip- Loaded Square Slot Antenna. IEEE Transactions on Antennas and Propagation, Vol. 51, No. 4, (April 2003) 3 (719-721)

Choi, J. \& Choi, N. (1997). Narrow-band interference suppression in direct sequence spread spectrum systems using a lattice IIR notch filter, Proceedings of IEEE Int. Conf. Acoustics, Speech, Signal Processing (ICASSP), pp. 1881-1884, Munich, Germany, April 1997

Denidni, T.A., and Habib, M.A. (2006). Broadband Printed CPW-fed Slot Antenna. IEE Electronics Letters, Vol. 42, No. 3 (February 2006)

Fathallah, H. \& Rusch, L. (1996). Enhanced blind adaptive narrowband interference suppression in dsss, Proceedings of IIEEE Global Telecommun. Conf.(GLOBECOM), pp. 545-549, London, November, 1996

Report and Order in the CommissionŠs Rules Regarding Ultra-Wideband Transmission Systems, Released by Federal Communications Commission(FCC), (April 2002).

Hong, S., Shin, J. Park, H. and Huang, J. (2007). Analysis of the band-stop techniques for ultra wideband antenna. Microwave and Optical Technology Letters, Vol. 49, No. 5, (May 2007) $5(1058-1062)$

Jang, Y.W. (2000). Broadband cross-shaped microstrip-fed slot antenna. IEE Electronics Letters, Vol. 36, No. 25, (December 2000) 3

Kasparis, T. (1991). Frequency independent sinusoidal suppression using median filters. IEEE Int. Conf. Acoustics, Speech, Signal Processing (ICASSP), pp. 612-615,Toronto, April, 1991

Kimouche, H.; Abed, D. \& Atrouz, B. (2009). Investigation on Microstrip-fed Modified Elliptical Monopole Antenna for UWB communication, Proceedings of 3rd European Conference on Antennas and Propagation (EuCAP), pp. 1450 - 1454, Berlin, Germany, March 23-27, 2009

Kobayashi, H. sasamori, T. Tobana, T. and Abe, K. (2007). A Study on Miniaturization of Printed Disc Monopole Antenna for UWB Applications Using Notched Ground Plane. IEICE Trans. Commun., Vol.E90-B, No.09, (September 2007)

Lee, H.-L., Lee, H.-J., Yook, J. -G. and Park, H. K. (2002). Broadband Planar Antenna having Round Corner Rectangular Wide Slot. Antennas and Propagation Society International Symposium, Vol. 2, (June 2002) 4 (460-463)

Liang, P.Li. and Chen,X. (2006). Study of Printed Elliptical/Circular Slot Antennas for Ultrawideband Applications Communication. IEEE Transaction on Antennas and Propagation, Vol. 54, No. 6 (June 2006) 6 (1670-1675)

Lim, T. J. \& Rasmussen, L. K. (1996). Adaptive cancelation of narrowband signal sin overlaid CDMA systems, Proceedings of IEEE Int. Workshop Intelligent Signal Processing and Communication Systems, pp. 1648-1652, Singapore, November, 1996 
Liu, Y.F., Lau, K. L., Xue, Q. and Chan, C. H. (2004). Experimental studies of printed wide-slot antenna for wide-band applications. IEEE Antennas and Wireless Propagation Letters, Vol. 3, (December 2004) 3 (273-275)

Medley, M. (1997). Narrow-band interference excision in spread spectrum systems using lapped transforms. IEEE Trans. Commun., Vol. 45, No. 9, (November 1997) 11 (14441455)

Poor, H., V. and Wang, X. (1997). Code-aided interference suppression in DS/CDMA spread spectrum communications. IEEE Trans. Commun., Vol. 45, No. 9, (September 1997) 11 $(1101-1111)$

Proakis, J. (1996). Interference suppression in spread spectrum systems. IEEE Int. Symp. on Spread Spectrum Techniques and Applications, Vol. 1, (September 1996) 8 (259-266)

Rusch, L. and Poor, H. (1994). Narrowband interference suppression in CDMA spread spectrum communications. IEEE Personal Commun. Mag., Vol. 42, (April 1994) 11 (19691979)

Rusch, L. and Poor, H. (1995). Multiuser detection techniques for narrowband interference suppression in spread spectrum communications. IEEE Trans. Commun., Vol. 42, (April 1995) 11 (1727-1737)

Sadat, S., Fardis, M., Geran, F. and Dadashzadeh, G. (2007). A Campact Microstrip Square Ring Slot Antenna for UWB Aplications. Progress In Electromagnetic Research (PIER), Vol. 67 (June 2007) 7 (173-179)

Soliman, E. A. Brebels, S. Beyne, E. and Vandenbosch, G. A. E. (1999). CPW-fed cusp antenna. Microwave and Optical Technology Letters, Vol. 22, No. 4, (August 1999) 2 (12056-12057)

Sorbello, G., Consoli, F. and Barbarino, S. (2002). Numerical and Experimental Analysis of a Circular Slot Antenna for UWB Communication. Microwave and Optical Technical Letters, Vol. 44, No. 5 (June 2005) 6 (465-470)

Sze, J.-Y., Hsu, C.-I.G. and Jiao, J.-J. (2006). CPW-fed circular slot antenna with slit back-patch for 2.4/5 GHz dual-band operation. IEE Electronics Letters, Vol. 42, No. 10, (May 2006)

Wang, F.-J., Yang, X.-X., Zhang, J.-S., Gao, G.-P. and Xiao, J.-X. (2008). A band-notched ring monoplole antenna. Microwave and Optical Technology Letters, Vol.50, No.7, (July 2008) 3 (1882-1884)

Weaver, R. D. (1997). Frequency domain processing of ultra-wideband signals. IEEE Asilomar Conf. Signals, Systems Computers, pp. 1221-1224,Pacific Grove, CA, November, 2003

Hong, S., Shin, J. Park, H. and Huang, J. (2007). The band-notch function for a compact coplanar waveguide fed super-wideband printed monopole. Microwave and Optical Technology Letters, Vol. 49, No. 11, (November 2007) 3 (2769-2771)

Yuan, T., Qiu, C.-W., Li, L.-W., Leong, M. S. and Zhang, Q. (2008). Elliptically shaped ultra wideband patch antenna with band-notch features. Microwave and Optical Technology Letters, Vol. 50, No. 3, (March 2008) 3 (736-738) 


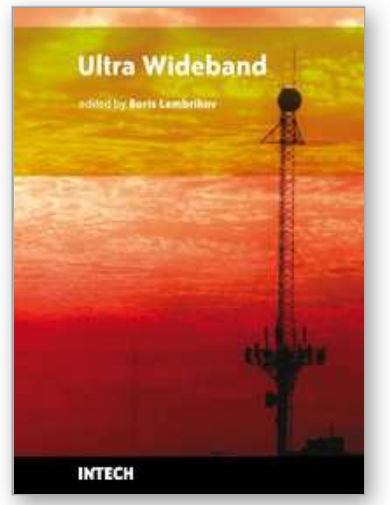

\author{
Ultra Wideband \\ Edited by Boris Lembrikov
}

ISBN 978-953-307-139-8

Hard cover, 458 pages

Publisher Sciyo

Published online 17, August, 2010

Published in print edition August, 2010

Ultra wideband technology is one of the most promising directions in the rapidly developing modern communications. Ultra wideband communication system applications include radars, wireless personal area networks, sensor networks, imaging systems and high precision positioning systems. Ultra wideband transmission is characterized by high data rate, availability of low-cost transceivers, low transmit power and low interference. The proposed book consisting of 19 chapters presents both the state-of-the-art and the latest achievements in ultra wideband communication system performance, design and components. The book is addressed to engineers and researchers who are interested in the wide range of topics related to ultra wideband communications.

\title{
How to reference
}

In order to correctly reference this scholarly work, feel free to copy and paste the following:

Djamel Abed and Hocine Kimouche (2010). Design and Characterization of Microstrip UWB Antennas, Ultra Wideband, Boris Lembrikov (Ed.), ISBN: 978-953-307-139-8, InTech, Available from:

http://www.intechopen.com/books/ultra-wideband/design-and-characterization-of-microstrip-uwb-antennas-

\section{INTECH}

open science | open minds

\section{InTech Europe}

University Campus STeP Ri

Slavka Krautzeka 83/A

51000 Rijeka, Croatia

Phone: +385 (51) 770447

Fax: +385 (51) 686166

www.intechopen.com

\section{InTech China}

Unit 405, Office Block, Hotel Equatorial Shanghai

No.65, Yan An Road (West), Shanghai, 200040, China

中国上海市延安西路65号上海国际贵都大饭店办公楼405单元

Phone: +86-21-62489820

Fax: $+86-21-62489821$ 
(C) 2010 The Author(s). Licensee IntechOpen. This chapter is distributed under the terms of the Creative Commons Attribution-NonCommercialShareAlike-3.0 License, which permits use, distribution and reproduction for non-commercial purposes, provided the original is properly cited and derivative works building on this content are distributed under the same license. 